\title{
Paronychia and granulation tissue formation during treatment with isotretinoin*
}

\author{
Daniela de Almeida Figueiras ${ }^{1}$ \\ Ayana Karla de Oliveira Ferreira Marinho ${ }^{1}$ \\ Renata Cavalcanti Cauas ${ }^{1}$
}

\author{
Ticiana Batista Ramos ${ }^{1}$ \\ Milena Soneley Mendonça Bezerra ${ }^{1}$
}

DOI: http:/ / dx.doi.org/10.1590/abd1806-4841.20163817

\begin{abstract}
This paper describes the association of two unusual side effects of treatment with isotretinoin for severe acne: paronychia and excess granulation tissue in the nails furrows. We report a case of male patient aged 19 years, who in the course of the 36th week of treatment with isotretinoin for acne grade III showed erythema, edema, excess granulation tissue and onychocryptosis in various nail beds of hands and feet, with no history of trauma associated. A literature review revealed few reports of these adverse events, and two clinical patterns of exuberant granulation tissue has been described: one in periungual location and other in lesions of previous acne. The rarity and lack of knowledge on the best treatment for granuloma-like reactions make this theme a considerable challenge.
\end{abstract}

Keywords: Paronychia; Granulation tissue; Retinoids

\section{INTRODUCTION}

Isotretinoin is effective and widely used in the treatment of nodulocystic acne, acne conglobata, acne with risk of permanent scarring and those resistant to the use of systemic antibiotics and topical agents, as indicated in the letter from Kanigsberg \& Des Groseilliers. ${ }^{1}$

Adverse events of isotretinoin are well known as teratogenicity, myalgias and arthralgias, hypertriglyceridemia, hypercholesterolemia and elevated transaminases.

It is also associated with numerous adverse events including skin cheilitis, facial dermatitis, xerosis, rash, conjunctivitis, epistaxis, photosensitivity and dryness of mucous membranes. These are commonly observed and generally do not limit its use.

Rarely patients may have stimulation of granulation tissue, leading to pyogenic granuloma eruptions of acne lesions in areas of trauma and in nail folds; paronychia may also occur. ${ }^{2,3}$ Knowing these unusual adverse events is important for the clinical management of patients, but its exact pathogenesis remains unclear.

\section{CASE REPORT}

Man, aged 19 years, with acne grade III, without comorbidities, pre-existing nail problems or prior use of medication. He started treatment with isotretinoin at a dose of $40 \mathrm{mg} /$ day $(0.54 \mathrm{mg} / \mathrm{kg} /$ day $)$.

In the sixth month of treatment, the patient presented edema, erosion and periungual erythema with serous discharge in 20 nails and onychocryptosis with excessive granulation tissue on toes. He reported to have undergone treatment with "topic creams" and compresses with boric acid solution prescribed in the emergency department, with improvement of the lesions on the hands. Upon returning to our service, the patient showed lesions in the first and second toes bilaterally and on the right toe (Figures 1, 2 and 3).

Received on 05.07.2014

Approved by the Advisory Board and accepted for publication on 04.11.2014

Study performed at Instituto Materno Infantil Professor Fernando Figueira (IMIP) - Recife (PE), Brazil.

Financial Support: None.

Conflict of Interest: None.

1 Instituto Materno Infantil Professor Fernando Figueira (IMIP) - Recife (PE), Brazil.

(C2016 by Anais Brasileiros de Dermatologia 
Treatment with oral antibiotics was performed, with course of prednisone $40 \mathrm{mg} /$ day, compress with boric acid solution and guidance on the use of appropriate footwear. The isotretinoin was maintained until obtaining a cumulative dose of $120 \mathrm{mg} / \mathrm{kg}$, totaling 7 months.

After the end of treatment with isotretinoin, the patient evolved with improvement of paronychia and granulation tissue on toes, but with persistence of onychocryptosis in hallux valgus. Subsequently, the patient was submitted to matricectomy with complete resolution of the disease (Figure 4).

\section{DISCUSSION}

Isotretinoin was first introduced in the United States in 1982 for the treatment of nodulocystic acne, be-

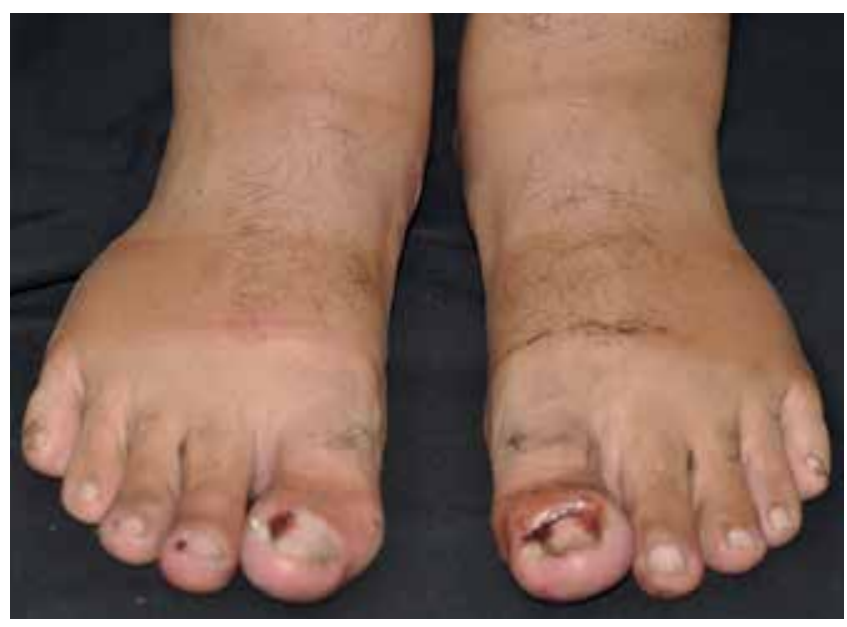

FIGURE 1:Paronychia and granulation tissue in feet, secondary to the use of isotretinoin

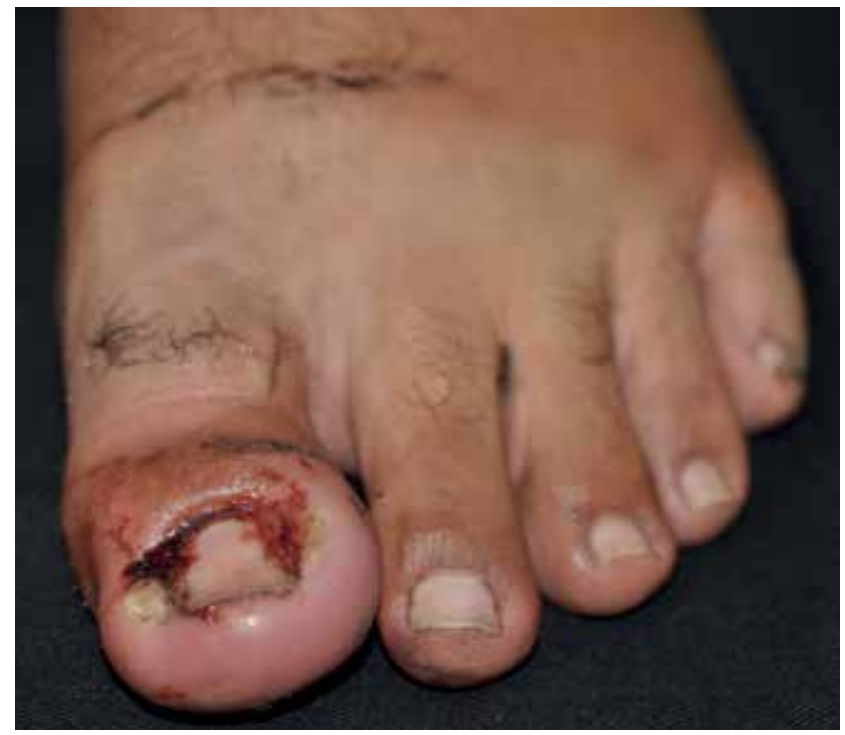

Figure 2: Pyogenic-like granuloma and paronychia in lateral edge of the first and second right toes

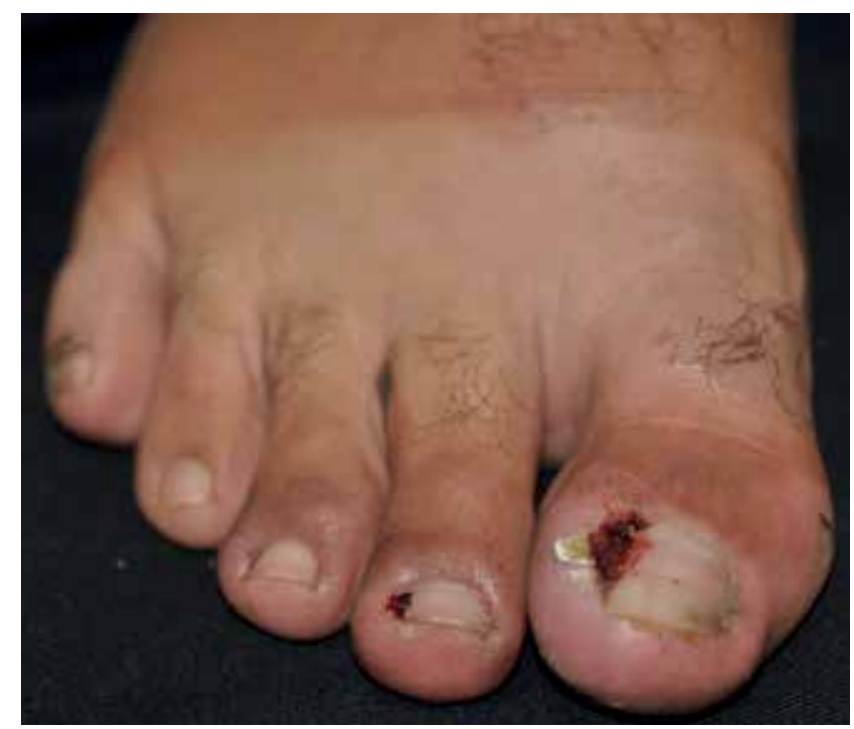

Figure 3:Excess of periungueal granulation tissue and paronychia, located in the first left toe

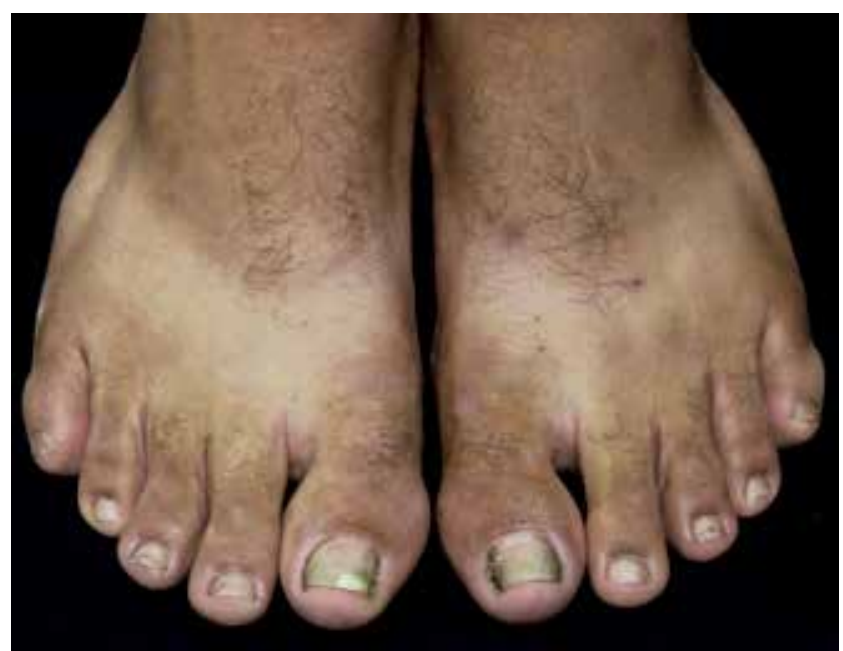

FIgURE 4: Two months after the completion of matricectomy: patient presented resolution of onicocriptosis without recurrence of the lesions on toes

ing the only medication that affects all of the major etiological factors involved in acne. Although isotretinoin is a highly effective drug, its clinical use has always been associated with reports of adverse events with several implications for the patient. It is therefore essential that physicians be aware of the adverse events that may occur during therapy with isotretinoin. ${ }^{4}$

Exuberant granulation tissue is described in the literature in patients using isotretinoin for acne treatment, but its occurrence is rare with few reports described.

The largest series conducted in 1988 reported 4 cases of paronychia caused by excessive growth of the lateral and distal nail folds, with an excess of granulation tissue associated. ${ }^{5}$ Multiple fingers were involved 
in all patients and the attempt to restart isotretinoin in one patient led to the resurgence of previous lesions, suggesting causality.

The exact mechanism by which retinoids may lead to the development of granulation tissue in skin is not well known. Baran et al suggest that, in susceptible patients, excess retinoids would lead to exacerbation of their functions in epithelial level of the nail matrix, generating local exfoliative dermatitis, with accumulation of scales in the nail folds. ${ }^{6}$ The scales would act as foreign bodies, causing inflammation and formation of granulation tissue. The nail fragility may also lead to the formation of nail spicules that, when introduced in the periungual tissue, would stimulate the appearance of granulation tissue and the ingrown toenail. Finally, the skin fragility of the periungual tissue under high doses of retinoids, associated with trauma and/or local bacterial infection, may stimulate the formation of granulation tissue.

Isotretinoin is also known to cause exuberant granulation tissue or pyogenic-like granuloma lesions in acne sites between the $3^{\text {rd }}$ and $12^{\text {th }}$ week of treatment. ${ }^{7}$ Reuben et al. suggest that, according to the characteristics of the treatment group, such event may not be as rare as previously thought. They observed the occur- rence of exuberant granulation tissue in 3 patients out of a total of 16 who used the drug. ${ }^{8}$ Therefore, it is reasonable to suggest that it would cause such changes in other parts of the body.

In addition, periungual exuberant granulation tissue of both fingers and toes is a documented adverse event of other retinoids therapies. Campbell et al reported 6 patients who develop this complication during therapy with etretinate for psoriasis. ${ }^{9}$ These lesions appear to be idiosyncratic and unrelated to the daily dose or total cumulative dose. Similar comment can be made regarding our patient who developed the first lesions with 6 months of treatment without having any change in the dosages used.

Thus, the knowledge of this unusual adverse event is important for the clinical management of patients treated with isotretinoin, and it seems that it is not necessary to discontinue it for the resolution of the lesion. Thus, advantages and disadvantages of discontinuing therapy for this problem should be carefully weighed. According to the literature, a course of 2-3 weeks of topical steroid and antibiotic on the occlusion is the first line of treatment for periungual pyogenic granuloma. ${ }^{10}$ In cases where the local treatment is insufficient, surgical removal becomes necessary.

\section{REFERENCES}

1. Kanigsberg N, DesGroseilliers JP. Use of 13-cis-retinoic acid in cystic acne. Can Med Assoc J. 1983;129:224, 228.

2. Exner JH, Dahod S, Pochi PE.. Pyogenic granuloma-like acne lesions during isotretinoin therapy. Arch Dermatol. 1983;119:808-11.

3. Brelsford M, Beute TC. Preventing and managing the side effects of isotretinoin. Semin Cutan Med Surg. 2008;27:197-206.

4. Charakida A, Mouser PE, Chu AC. Safety and side effects of the acne drug, oral isotretinoin. Expert Opin Drug Saf. 2004;3:119-29.

5. Bigby M, Stern RS. Adverse reactions to isotretinoin. A report from the Adverse Drug Reaction Reporting System. J Am Acad Dermatol. 1988;18:543-52.

6. Baran R. Etretinate and the nails (study of 130 cases) possible mechanisms of some side-effects. Clin Exp Dermatol. 1986;11:148-52.

7. Hagler J, Hodak E, David M, Sandbank M. Facial pyogenic granuloma-like lesions under isotretinoin therapy. Int J Dermatol. 1992;31:199-200.

8. Azulay RD, Abulafia LA, Costa JAN, Sodré CT. Tecido de granulação exuberante: efeito colateral da terapêutica com isotretinoína. An Bras Dermatol. 1985;60:17982.

9. Campbell JP, Grekin RC, Ellis CN, Matsuda-John SS, Swanson NA, Voorhees JJ. Retinoid therapy is associated with excess granulation tissue responses. J Am Acad Dermatol. 1983;9:708-13.

10. Piraccini BM, Bellavista S, Misciali C, Tosti A, de Berker D, Richert B. Periungual and subungual pyogenic granuloma. Br J Dermatol. 2010;163:941-53.

\author{
MAILING ADDRESS: \\ Daniela de Almeida Figueiras \\ Rua dos Coelhos, 300 \\ Boa Vista \\ 50070-902 - Recife -PE \\ Brazil \\ Email:danifigueiras@hotmail.com
}

How to cite this article: Figueiras DA, Ramos TB, Marinho AKOF, Bezerra MSM, Cauas RC. Paronychia and granulation tissue formation during treatment with isotretinoin. An Bras Dermatol. 2016;91(2):223-5. 